\title{
Reevaluating split-fovea processing in word recognition: Hemispheric dominance, retinal location, and the word-nonword effect
}

\author{
Timothy R. Jordan, Kevin B. Paterson, and Stoyan Kurtev \\ University of Leicester, Leicester, England
}

\begin{abstract}
Many studies have claimed that hemispheric projections are split precisely at the foveal midline and so hemispheric asymmetry affects word recognition right up to the point of fixation. To investigate this claim, four-letter words and nonwords were presented to the left or right of fixation, either close to fixation in foveal vision or farther from fixation in extrafoveal vision. Presentation accuracy was controlled using an eyetracker linked to a fixation-contingent display. Words presented foveally produced identical performance on each side of fixation, but words presented extrafoveally showed a clear left-hemisphere (LH) advantage. Nonwords produced no evidence of hemispheric asymmetry in any location. Foveal stimuli also produced an identical word-nonword effect on each side of fixation, whereas extrafoveal stimuli produced a word-nonword effect only for LH (not right-hemisphere) displays. These findings indicate that functional unilateral projections to contralateral hemispheres exist in extrafoveal locations but provide no evidence of a functional division in hemispheric processing at fixation.
\end{abstract}

Nerve fibers carrying information about stimuli falling in the left visual hemifield project to the right lateral geniculate nucleus (LGN) and then to the visual cortex of the right cerebral hemisphere (RH), whereas fibers carrying information about stimuli falling in the right visual hemifield project to the left LGN and then to the visual cortex of the left cerebral hemisphere (LH). Thus, with appropriate experimental control, stimuli can be projected contralaterally to whichever cerebral hemisphere is chosen by the experimenter to reveal hemispheric asymmetries in processing.

Using this technique, numerous studies have shown that words presented outside foveal vision are processed more efficiently when presented to the right of fixation than when presented to the left (for overviews, see Bradshaw \& Nettleton, 1983; Chiarello, 1988; Hellige, 1993). Although the precise nature of the processes that underlie the perception of words in each hemisphere is widely debated (e.g., Bub \& Lewine, 1988; Burgund \& Marsolek, 1997; Ellis, 2004; Ellis, Young, \& Anderson, 1988; Jordan \& Patching, 2003a, 2003b; Jordan, Patching, \& Milner, 1998, 2000; Jordan, Patching, \& Thomas, 2003a, 2003b; Jordan, Redwood, \& Patching, 2003; Reuter-Lorenz \& Baynes, 1992), there seems little doubt that this advantage for words reflects privileged access to specialized LH processing of linguistic information.

However, although the projection of information outside foveal vision to the contralateral hemisphere is well established, the projection of information around the point of fixation has become a matter of debate in word recognition research. At the origin of this debate is the widely accepted view that a sizable area of overlap (typically regarded as $1^{\circ}-3^{\circ}$ wide) exists around the point of fixation within which information projects (bilaterally) to both the $\mathrm{LH}$ and the RH (for relevant reviews, findings, and opinions, see Brandt, Stephan, Bense, Yousry, \& Dieterich, 2000; Bunt \& Minckler, 1977; Fendrich, Wessinger, \& Gazzaniga, 1996; Gazzaniga, 2000; Jordan \& Paterson, in press; Leventhal, Ault, \& Vitek, 1988; Lindell \& Nicholls, 2003; Reinhard \& Trauzettel-Klosinski, 2003; Stone, 1966; Stone, Leicester, \& Sherman, 1973; Trauzettel-Klosinski \& Reinhard, 1998). Indeed, researchers investigating hemispheric asymmetries in word recognition often present stimuli at least $2^{\circ}$ to the left or right of a central fixation point to ensure that these stimuli are presented at eccentricities that are safely beyond the boundary of bilateral projection, and so project unilaterally to either the LH or the RH (for a review, see Lindell \& Nicholls, 2003). However, in contrast, some researchers have proposed that hemispheric asymmetries affect word recognition right up to the point of fixation, because each fovea is divided precisely at its vertical midline and so all information on either side of this midline projects (unilaterally) to the contralateral hemisphere (for reviews, see Jordan \& Paterson, in press; Lavidor \& Walsh, 2004; Lindell \& Nicholls, 2003). Thus, according to this split-fovea theory of word recognition (hereafter, SFT), information presented to the left of fixation will project to the $\mathrm{RH}$, and 
information presented to the right of fixation will project to the $\mathrm{LH}$, even when this information is presented within foveal vision, and this division in hemispheric processing at the point of fixation produces substantial effects on word recognition (e.g., Shillcock, Ellison, \& Monaghan, 2000; Shillcock \& McDonald, 2005).

Although advocates of SFT have argued that the theory is supported by anatomical evidence (e.g., Leff, 2004), the issue is complex and far from resolved (e.g., Brandt et al., 2000; Bunt \& Minckler, 1977; Fendrich et al., 1996; Gazzaniga, 2000; Leventhal et al., 1988; Lindell \& Nicholls, 2003; Reinhard \& Trauzettel-Klosinski, 2003; Stone, 1966; Stone et al., 1973; Trauzettel-Klosinski \& Reinhard, 1998; for a critical review, see Jordan \& Paterson, in press). Consequently, SFT researchers have also attempted to reveal functional evidence of split-foveal processing by directly observing the influence on word recognition of presenting stimulus information at different eccentricities around the point of fixation (e.g., Brysbaert, 1994; Brysbaert, Vitu, \& Schroyens, 1996; Hunter, Brysbaert, \& Knecht, 2007; Lavidor, Ellis, Shillcock, \& Bland, 2001; Martin, Thierry, Démonet, Roberts, \& Nazir, 2007; see also Brysbaert, 2004; Ellis, 2004). For example, Brysbaert et al. investigated recognition of words presented at various eccentricities around a central fixation point. Across the experiment, words were offset to the left or right of the fixation point, so that they either straddled the point at various locations or were shown entirely to the left or right in locations close to the fixation point. The findings showed a word recognition advantage when most of the letters in a word, or words in their entirety, were shown to the right of the fixation point. Thus, according to the logic of this research, word recognition was determined by the hemisphere to which the letters presented to the left and right of fixation were projected, and a processing advantage was produced when most or all of these letters were presented to the right of the fixation point because (in line with SFT) all letters to the right of fixation projected to the LH.

The logic behind all of these studies is that if word recognition is affected by unilateral contralateral hemispheric projections that occur right up to the point of fixation (as SFT proposes), this division in processing will be revealed by hemispheric asymmetries in performance even when information is presented within foveal vision, close to fixation. However, on closer inspection, the support for SFT becomes less compelling.

First, it is well established that participants have great difficulty monitoring and controlling their eye movements when attempting to fixate a specified location, and accurate fixation cannot be ensured without external monitoring and control (i.e., by using an eyetracking device; for reviews, see Gazzaniga, 2000; Jordan et al., 1998, 2000; see also Anliker, 1977; Batt, Underwood, \& Bryden, 1995; Findlay \& Kapoula, 1992; Jones \& Santi, 1978; Jordan \& Patching, 2006; Jordan et al., 2003a, 2003b; Jordan \& Paterson, in press; Patching \& Jordan, 1998; Sugishita, Hamilton, Sakuma, \& Hemmi, 1994; Terrace, 1959). However, participants in the studies by Brysbaert (1994), Brysbaert et al. (1996), Hunter et al.
(2007), Lavidor et al. (2001), and Martin et al. (2007) were only instructed to fixate the designated fixation location in each experiment (sometimes accompanied by a secondary fixation task), with no external monitoring or control to determine which locations were actually fixated. ${ }^{1}$ Indeed, Jordan, Paterson, and Stachurski (in press) used the same stimuli, displays, and procedures as Lavidor et al. (2001) but also used an eyetracker to show the locations of fixations actually made by participants. The findings revealed that the participants failed to fixate the designated location on approximately $50 \%$ of the trials, and inaccurate fixations fell at least $0.25^{\circ}$ (over two letters) and up to $1^{\circ}$ (more than the width of a complete word) away. The frequency and extent of these inaccurate fixations cast considerable doubt on the notion that, without external monitoring or control, stimuli presented around the point of fixation can be projected reliably to the required side of fixation and, therefore (if SFT is correct), to the appropriate hemisphere.

Second, the problem of accurately projecting foveal information to the appropriate hemisphere in previous studies supporting SFT is complicated by the use of stimuli that exceeded the area of foveal vision. In particular, because the existence of unilateral contralateral projections outside foveal vision is well established and not contentious (for a review, see Gazzaniga, 2000), support for the view that unilateral contralateral projections affect word recognition right up to the point of fixation (i.e., SFT) would be more convincing if the stimuli used did not extend into extrafoveal locations. Lavidor et al. (2001) reported using stimuli that fitted entirely within foveal vision (up to $1.5^{\circ}$ either side of fixation). However, the studies of Brysbaert (1994), Brysbaert et al. (1996), Hunter et al. (2007), and Martin et al. (2007) were less appropriate. For example, Brysbaert (1994; see also Brysbaert et al., 1996; Hunter et al., 2007) presented stimuli of three, four, five, seven, and nine letters in length, but only stimuli of three and four letters were sufficiently physically small to always be shown entirely within foveal vision (notwithstanding the problems of fixation accuracy already described). For all other lengths, stimuli frequently exceeded the area of foveal vision (by up to $1.5^{\circ}$ ), making it unclear how effects of presenting stimuli to the left and right of the designated fixation point reflected the influence of unilateral projections in foveal, not extrafoveal, vision. A similar (but even greater) problem exists with the five-letter stimuli used by Martin et al., which subtended a horizontal angle of $6.65^{\circ}$ (five letters subtend about $1.25^{\circ}$ in normal reading; see, e.g., Rayner \& Pollatsek, 1989). Depending on how stimuli were displayed, either more than $75 \%$ of each stimulus extended unilaterally into extrafoveal locations or each stimulus extended into extrafoveal locations on both sides of the required fixation point.

More recent studies have overcome these problems, and their findings provide no evidence to support SFT. Jordan, Paterson, and Stachurski (in press) used the same stimuli, displays, and procedures as those in Lavidor et al. (2001) but, over the three experiments conducted, found no evidence to support the findings of Lavidor et al. 
(2001), even when accurate fixations were ensured using an eyetracking device (see also Jordan, Paterson, Kurtev, $\& \mathrm{Xu}$, in press-b). Instead, each experiment showed that word recognition was simply better when fixations were made near the beginning of words rather than near the end, and so replicated the well-established optimal viewing position effect previously reported in the literature (e.g., O’Regan, 1981; O'Regan, Lévy-Schoen, Pynte, \& Brugaillère, 1984; Stevens \& Grainger, 2003). As Jordan, Paterson, and Stachurski (in press) concluded, not only were Lavidor et al.'s (2001) findings not replicated, but also the findings that were obtained can readily be explained by established effects of fixation location on word recognition, without the need to involve putative influences of split-foveal processing. In another study, Jordan, Paterson, and Stachurski (2008) presented words entirely within either foveal or extrafoveal locations, to either the left or right of a central fixation point, and ensured accurate fixation using an eyetracker. The experiment revealed that, although there was a clear LH advantage for words presented at eccentricities of $2^{\circ}$ and more, the same words presented close to fixation (and falling entirely within foveal vision) produced levels of performance that were the same each side of fixation. Therefore, whereas these findings indicate that functional unilateral projections to different, contralateral hemispheres exist for extrafoveal presentations, they provide no evidence of this division in hemispheric processing for foveal presentations.

The present study builds on these recent findings by investigating more closely the existence of divided foveal projections to hemispheric processes of word recognition. In particular, according to SFT, a functional split in word recognition occurs at the point of fixation because direct access to each hemisphere is divided precisely at the foveal midline and so dominant processes specialized for word recognition (located in the LH of most individuals; see, e.g., Knecht et al., 2000) can be accessed directly only by words presented to the right of fixation, even when words are presented in foveal vision. The findings of Jordan, Paterson, and Stachurski (2008) argue against this notion of a functional foveal split because an LH advantage for words occurred only when stimuli were projected outside foveal vision. However, it remains to be seen whether this pattern of performance reflects access to processes specialized for word recognition or merely processing at a more basic level (e.g., letter discriminability; Bouma, 1973; Loomis, 1978) where words are perceived only as disjoint strings of letters. If the latter, the presence of LH dominance for extrafoveal words and the absence of LH dominance for foveal words may be attributed to irrelevant differences in early stages in the processing of any string of letters, rather than to a pattern of effects that reflects access to hemispheric processes specialized for word recognition. Indeed, in line with this view, some advocates of SFT have suggested that even if foveal information does project bilaterally, this information is likely to be highly impoverished and too crude to contribute to word recognition (see, e.g., Brysbaert, 2004; Lavidor et al., 2001; Lavidor, Ellison, \& Walsh, 2003; Shillcock et al., 2000; Shillcock \& McDonald,
2005). Thus, evidence of the involvement of processes of word recognition in lateralized foveal displays would help assess more precisely the putative involvement of divided foveal hemispheric projections in word recognition.

One way to reveal the involvement of processes specialized for word recognition is to contrast performance between words and nonwords. Numerous studies using a variety of normal (i.e., not lateralized) displays presented briefly in the center of the visual field have shown that words are perceived better than illegal strings containing minimal orthographic structure (the word-nonword effect; see, e.g., McClelland \& Rumelhart, 1981; Reicher, 1969; Rumelhart \& McClelland, 1982; Wheeler, 1970), and the widespread interpretation of this superiority is that it reflects the ability of words to access processes specialized for word recognition (e.g., Grainger \& Jacobs, 1994, 1996; Jacobs \& Grainger, 1994; Johnston \& McClelland, 1980; Jordan et al., 2000; Jordan et al., 2003a, 2003b; McClelland \& Rumelhart, 1981, 1988; Paap, Newsome, McDonald, \& Schvaneveldt, 1982; see also Carr \& Pollatsek, 1985). Thus, when stimuli are presented briefly, observers are more likely to encode information from words than from nonwords, which, in turn, produces a processing advantage for word stimuli. Moreover, other studies using similar displays of words and nonwords but presented as extrafoveal lateralized displays (e.g., Jordan et al., 2000; Jordan et al., 2003a, 2003b; Reuter-Lorenz \& Baynes, 1992) have reported that word-nonword effects occur when stimuli are projected to the LH, but are absent (or greatly reduced) when stimuli are projected to the RH. Thus, when stimuli are presented in lateralized displays outside foveal vision, only stimuli projected to the LH produce a substantial word-nonword effect, because only these stimuli directly activate LH processes specialized for word recognition. Consequently, the indications are that the word-nonword effect reflects selective activation of processes specialized for word perception and that these processes are lateralized to the LH.

This contrast between the effect produced when words and nonwords are projected to each hemisphere provides a valuable manipulation for revealing the existence and nature of a functional foveal split in word recognition. In particular, if SFT is correct, unilateral projections to each contralateral hemisphere should enable words (but not nonwords) to directly activate LH processes of word recognition at any point to the right of fixation (but not the left), and so produce LH advantages for words and LH word-nonword effects for displays in extrafoveal and foveal locations. Thus, even if words alone cannot provide evidence of a functional split in foveal processing (Jordan et al., 2008), differences in the relative performance produced by words and nonwords on each side of fixation may reveal this split and provide important indications that processes of word recognition were activated by these foveal presentations.

If SFT is not correct, however, and unilateral foveal projections to each contralateral hemisphere do not influence word recognition, only words presented in extrafoveal locations should produce an LH advantage. Moreover, if no functional foveal split exists, foveal presentations to 
the left and right of fixation should both produce similar word-nonword effects, because both presentations should project to the LH (as well as to the $\mathrm{RH}$ ) and so directly activate LH processes of word recognition. Indeed, if no functional foveal split exists, the word-nonword effect should be absent (or at least greatly reduced) only with extrafoveal displays projected to the $\mathrm{RH}$, because only these displays should provide no direct activation of $\mathrm{LH}$ processes of word recognition.

Accordingly, the present research reevaluated the fundamental claim of SFT that a division in hemispheric processing at the point of fixation plays a functional role in word recognition. To investigate this claim, words and nonwords were presented to the left or right of fixation at eccentricities that placed them either entirely in foveal locations (with medial edges $0.25^{\circ}$ from fixation) or entirely in extrafoveal locations (with medial edges $2.20^{\circ}$ from fixation). As in some previous studies of hemispheric asymmetry, performance in each location was assessed using the Reicher-Wheeler task (after Reicher, 1969, and Wheeler, 1970) to provide an assessment of the wordnonword effect and LH dominance for word recognition that would not be contaminated by perceptual asymmetry and guesswork (see, e.g., Jordan et al., 1998, 2000; Jordan et al., 2003a, 2003b; Reuter-Lorenz \& Baynes, 1992). ${ }^{2}$ An eyetracking system linked to a computer-controlled, fixation-contingent display ensured accurate fixation when each word was presented. All participants were selected to be LH-dominant for language, and all had previously shown the well-established LH advantage for words presented in extrafoveal locations.

\section{METHOD}

\section{Participants}

Sixteen native English speakers, 18-35 years of age, from the University of Leicester were paid for participating. All the participants had at least normal (or corrected-to-normal) acuity, determined by a Bailey-Lovie Eye Chart, and were right-handed, determined by a score of $100 \%$ on a revised Annett Handedness Questionnaire (Annett, 1970).

\section{Stimuli}

Following previous studies of hemispheric asymmetry, performance in each location was assessed using the Reicher-Wheeler task to provide an assessment of LH dominance for word recognition that is not contaminated by perceptual asymmetry and guesswork and which demonstrates processes of word perception (see, e.g., Jordan et al., 1998, 2000; Jordan et al., 2003a, 2003b; ReuterLorenz \& Baynes, 1992). Accordingly, 64 four-letter words with a mean frequency of 87 per million (according to the CELEX database; Baayen, Piepenbrock, \& Gulikers, 1995) were used in the experiment. Following the requirements of the Reicher-Wheeler task, words were selected to form matched pairs in which the members of each pair differed by just one letter (e.g., read, road) and these differences occurred equally often at each of the four letter positions across all stimuli. Matched nonword stimuli were constructed for each pair, using custom software (Jordan \& Monteiro, 2003) to rearrange the three noncritical letters in each word to form unpronounceable nonwords that had minimal orthographic structure but shared the same critical letter in the same serial position (e.g., the words read and road formed the nonwords aedr and aodr, respectively). An additional 16 pairs of four-letter words and nonwords were constructed to provide 32 practice stimuli at the beginning of each session.

The stimuli were presented in lowercase Arial font at foveal and extrafoveal locations to the left and right of a central fixation point. The physical size of the stimuli presented at foveal and extrafoveal locations was adjusted to avoid confounding effects of acuity on overall levels of performance (e.g., Drasdo, 1977) and to ensure that the stimuli were shown entirely in either foveal or extrafoveal locations. Accordingly, foveal stimuli subtended $0.55^{\circ}$ horizontally and had an $x$ height of $0.13^{\circ}$. The medial edges of these stimuli were $0.25^{\circ}$ from fixation. Extrafoveal stimuli subtended $1.10^{\circ}$ horizontally and had an $x$ height of $0.26^{\circ}$. The medial edges of these stimuli were $2.20^{\circ}$ from fixation. Preliminary testing had established that these sizes and eccentricities produced similar levels of overall performance for foveal and extrafoveal displays.

\section{Apparatus}

The stimuli were presented on a gamma-corrected high-definition 21-in. ViewSonic G220F display monitor at a resolution of 1,536 $\times$ 1,152 and a refresh rate of $60 \mathrm{~Hz}$. A Cambridge Research Systems VSG $2 / 5$ card controlled stimulus presentations and timing. Responses were collected via a Cambridge Research Systems CT3 buttonbox. The experiment was conducted in a sound-attenuated and darkened room, and displays were observed using a head restraint to ensure a constant viewing distance of $60 \mathrm{~cm}$. Fixation location was monitored monocularly via each participant's dominant eye (always the right eye; the left eye was occluded using a lightproof eye patch) using a Skalar IRIS eyetracking system (Cambridge Research Systems). The eyetracker was clamped to each participant's head, which in turn was clamped in a head brace throughout the experiment to prevent head movements. This arrangement allowed accurate and consistent measurement of fixation location in the experiment to within $5^{\prime}$ of arc (for further details, see Jordan \& Patching, 2006; Patching \& Jordan, 1998). The output of the tracker was recorded through the ADC input of the Cambridge Research Systems VSG 2/5 card, which also controlled the visual display (for further details, see Jordan et al., 1998, 2000).

\section{Design}

The participants took part in four sessions, one on each of 4 different days. Within each session, stimuli were selected pseudorandomly and assigned pseudorandomly to retinal locations so that 32 presentations (16 words, 16 nonwords) took place at each retinal location in each session (a total of 128 presentations). Across all sessions, each stimulus (word or nonword) was shown once in each retinal location.

\section{Procedure}

At the start of each trial, a single but clearly visible pixel (the fixation point) was presented at the center of the screen. The participants were required to fixate this point, and stimulus presentation was prevented until accurate fixation occurred continuously for $300 \mathrm{msec}$. When this criterion was satisfied, a stimulus (word or nonword) was presented for $16.67 \mathrm{msec}$ at one of the four locations. If fixation deviated from the fixation point before the presentation of the stimulus, presentation was immediately prevented and continued to be prevented until accurate fixation occurred again for at least 300 msec (see Patching \& Jordan, 1998, for further details of this procedure). No deviations in fixation occurred during the presentation of each stimulus. The target stimulus and its matched pair-mate were displayed $400 \mathrm{msec}$ after each target presentation, one above the other (randomly determined), and the participants decided which of these two stimuli had been shown by pressing the upper or lower key on the response box. The alternatives were presented in a size intermediate between the two sizes used for target presentations $\left(0.825^{\circ}\right)$ at the bottom of the screen well away from the locations at which targets were presented and stayed in view until a response was made. All alternatives were presented in up- 
percase Arial font to prevent simple visual matching between target and response.

\section{RESULTS}

Mean identification accuracy for words and nonwords presented at each of the four foveal and extrafoveal locations is shown in Figure 1. Overall levels of performance were closely matched for foveal and extrafoveal displays (75\% vs. $76 \%$ ), indicating that the size manipulations used in the experiment successfully matched visibility across foveal and extrafoveal locations.

The data for extrafoveal and foveal presentations were analyzed separately using a within-participants ANOVA with variables of hemisphere and stimulus type.

For extrafoveal stimuli, the ANOVA revealed main effects of hemisphere $\left[F(1,15)=6.73, p<.05, \eta^{2}=.31\right]$ and stimulus type $\left[F(1,15)=12.27, p<.01, \eta^{2}=.45\right]$ and an interaction between these two variables $[F(1,15)=$ $\left.8.05, p=.01, \eta^{2}=.35\right]$. Tukey tests showed an LH advantage for words $(85 \%$ vs. $74 \% ; p<.01)$ but not for nonwords $(72 \%$ vs. $72 \% ; p>.10)$, and a substantial wordnonword effect for LH stimuli $(85 \%$ vs. $72 \% ; p<.01)$ but not for RH stimuli (74\% vs. $72 \% ; p>.10)$.

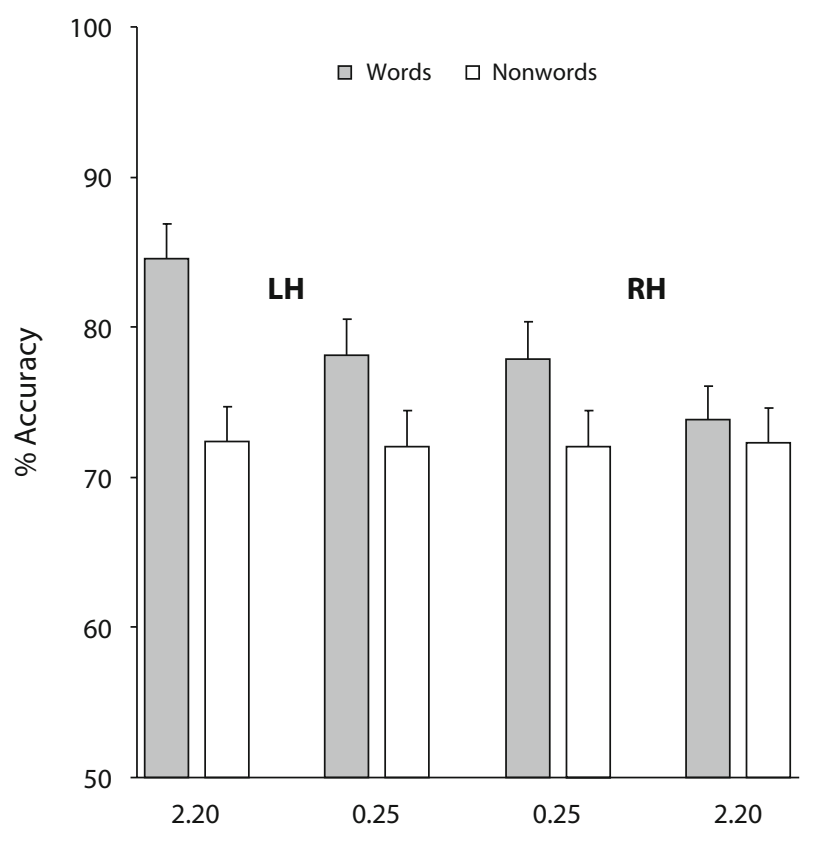

Stimulus Location

Figure 1. Mean percentages of correct responses (\% accuracy) to words and nonwords presented at each stimulus location (degrees of visual angle away from the fixation point). $\mathrm{LH}$, presentations intended for unilateral projection to the left hemisphere; RH, presentations intended for unilateral projection to the right hemisphere. Note that actual unilateral projections depend on where in the visual field divided access to hemispheric processing actually occurs. Overall levels of performance for foveal and extrafoveal displays were deliberately matched. Bars correspond to $95 \%$ confidence intervals (e.g., Loftus \& Masson, 1994).
For foveal stimuli, the ANOVA showed only a main effect of stimulus type $\left[F(1,15)=12.15, p<.01, \eta^{2}=.45\right]$. For all other effects, $F<1$. Tukey tests confirmed that an identical word-nonword effect was observed for LH and RH displays ( $78 \%$ vs. $72 \%$; both $p$ s $<.01)$.

\section{DISCUSSION}

The experiment reported in this article reassessed the claim, fundamental to SFT (e.g., Ellis, 2004; Lavidor \& Walsh, 2004; Shillcock et al., 2000; Shillcock \& McDonald, 2005), that each human fovea is split precisely at its vertical midline and, as a consequence, information at all locations to the left or right of fixation projects unilaterally to the contralateral hemisphere. Thus, although it is well established that recognition of words in extrafoveal locations is influenced by hemispheric asymmetry, due to unilateral projections to the contralateral hemisphere, SFT asserts that words in foveal locations right up to the point of fixation also project unilaterally to the contralateral hemisphere and that this division in hemispheric processing has substantive effects on word recognition.

The experiment revealed a number of findings indicating that no functional split in hemispheric processing occurs at the point of fixation. First, although there was a clear LH advantage for words presented extrafoveally, the same words presented within foveal vision produced levels of performance that were the same on each side of fixation. Nonwords produced no evidence of any hemispheric processing asymmetry in any location. Second, although extrafoveal stimuli produced a sizable wordnonword effect for LH displays and no word-nonword effect for RH displays, foveal displays produced a wordnonword effect that was identical on each side of fixation. These findings indicate that functional unilateral projections to different, contralateral hemispheres exist for extrafoveal presentations but provide no evidence of a division in hemispheric processing for foveal presentations (in our experiment, extending $0.80^{\circ}$ either side of fixation). Indeed, from the pattern of word-nonword performance obtained, direct activation of LH processes specialized for word recognition occurred with all displays except for extrafoveal displays projected to the $\mathrm{RH}$, indicating that only these displays provided no direct access to LH processes.

The pattern of word-nonword performance observed with extrafoveal displays closely resembles that reported previously in studies using lateralized displays presented outside foveal vision (e.g., Jordan et al., 2000; Jordan et al., 2003a). Specifically, the advantage for stimuli projected to the LH was available only for words; projection to the RH produced similar levels of performance for words and nonwords; and projection to the LH produced no change in nonword performance but a significant improvement in word performance, resulting in a wordnonword effect for LH stimuli. One interpretation of the word-nonword effect observed with normal (nonlateralized) displays is that performance with briefly presented words benefits from their ability to activate representa- 
tions for words (e.g., Grainger \& Jacobs, 1994, 1996; Jacobs \& Grainger, 1994; Johnston \& McClelland, 1980; McClelland \& Rumelhart, 1981, 1988; Paap et al., 1982; see also Carr \& Pollatsek, 1985). In particular, activated word representations offer an additional source of stimulus information that may also feed back to lower levels of representation (e.g., for individual letters; Johnston \& McClelland, 1980; McClelland \& Rumelhart, 1981, 1988; Paap et al., 1982). Thus, under brief presentation conditions, observers are more likely to "capture" information about the orthographic content of words than about that of nonwords. Adopting this logic, the pattern of effects we observed with extrafoveal displays suggests that effective access to visual word representations was available only for stimuli presented to the LH of the participants in our study. If we assume that briefly presented words are more likely to activate word representations when presented directly to a hemisphere in which these representations exist, the improved performance observed for words presented to the LH and the presence of a word-nonword effect only for stimuli presented to the LH suggest that only the LH of our participants contained a visual lexicon. However, although providing evidence of hemispheric asymmetry, the precise role of word representations in the effects we observed for extrafoveal displays is not fully resolved. For example, under normal (nonlateralized) viewing conditions, pseudowords produce superior report accuracy over random letter strings (e.g., Baron \& Thurston, 1973; Rumelhart $\&$ McClelland, 1982) and often show only a small deficit in performance, relative to words (e.g., Carr, Davidson, \& Hawkins, 1978; Manelis, 1974; McClelland \& Johnston, 1977; Spoehr \& Smith, 1975). Consequently, the improved performance observed for extrafoveal words presented to the LH and the presence of a word-nonword effect only for extrafoveal stimuli presented to the $\mathrm{LH}$ in our study may reflect better access to representations for letter groups as well as for whole words (e.g., Ans, Carbonnel, \& Valdois, 1998; Plaut, McClelland, Seidenberg, \& Patterson, 1996; Seidenberg \& McClelland, 1989). Future, fine-grained manipulations of the orthographic content of nonwords, coupled with the testing procedures adopted in our experiment, will help identify the representations underlying LH dominance for extrafoveal presentations. However, it is clear that, for foveal presentations, the essentially identical levels of accuracy produced either side of fixation provide no support for a functional division in hemispheric processing at fixation, for either words or nonwords.

The relative size of the word-nonword effect observed with foveal and extrafoveal displays may also be explained by the absence of a functional split in foveal processing. Whereas the unilateral projection of extrafoveal stimuli appears to have maximized the superiority for words over nonwords for LH presentations and minimized (i.e., removed) this superiority for RH presentations, the wordnonword effect observed for stimuli presented in foveal locations fell between these two levels. This suggests that when foveal stimuli were presented, the word-nonword effect was greater than that for extrafoveal stimuli projected (solely) to the RH, because foveal projections involved the LH, which improved performance with words. In a similar vein, when foveal stimuli were presented, the word-nonword effect was smaller than that for extrafoveal stimuli projected (solely) to the LH, because foveal projections involved the RH, which "diluted" performance with words. Thus, when stimulus visibility is equated across foveal and extrafoveal locations, hemispheric collaboration on word recognition may be less efficient than LH processing alone, perhaps due to interhemispheric interference (e.g., Querné, Eustache, \& Faure, 2000).

Advocates of SFT have argued that interhemispheric transmission is costly and, hence, the proposed anatomical split in each fovea means that projection to the nondominant hemisphere incurs processing costs even in foveal vision (e.g., Brysbaert, 1994; Brysbaert et al., 1996; Hunter et al., 2007; Lavidor et al., 2001). The findings we report do not support this view. Indeed (and notwithstanding the absence of clear anatomical support for foveal splitting), even if an anatomical split in foveal processing actually exists along the lines proposed by SFT, the findings we obtained suggest that this split has no functional influence on word recognition. Thus, even if human foveae are split anatomically, the transmission of information between the two hemispheres may be sufficiently rapid to obviate a functional role for this anatomical divide. As Dehaene, Cohen, Sigman, and Vinckier (2005) pointed out, callosal projections beyond V1 may have the structure necessary to ensure the continuity of receptive fields across the foveal midline and to allow convergence on common visual representations, which may, therefore, remove the functional impact of any initial foveal split. From the findings of the present study, however, the functional asymmetries in hemispheric processing that were apparent for extrafoveal displays indicate that similar interhemispheric communication is not available for the processing of words in extrafoveal locations.

Clearly, however, the finding that effects of hemispheric asymmetry were entirely absent for foveal presentations is consistent with the well-established view that a sizable area of overlap exists around the point of fixation within which information projects bilaterally to both hemispheres. However, advocates of SFT have suggested that even if foveal information does project bilaterally, this information is likely to be highly impoverished, to be slow to encode, and to contribute little to word recognition. For example, Brysbaert (2004) argued, on the basis of data from Fendrich et al. (1996), that any bilateral overlap in the processing of foveal information would not allow fast recognition of small letters and would be too crude for word recognition (see also, e.g., Lavidor et al., 2001; Lavidor et al., 2003; Shillcock et al., 2000; Shillcock \& McDonald, 2005). Yet, in the present experiment, despite the brevity of each display, the diminutive size of the letters in foveal stimuli, and the demanding nature of the task (identifying a letter string from two very similar alternatives), the absence of hemispheric asymmetry for foveal presentations was accompanied by high levels of identification 
accuracy for word stimuli and substantial word-nonword effects. Thus, the absence of hemispheric asymmetry in the recognition of foveal stimuli we observed offers no support for the notion of ineffectual bilateral foveal projections of visual information. Instead, such bilateral projections appear to support accurate identification of briefly presented, small word targets either side of fixation. In fact, on closer inspection, Fendrich et al.'s findings are also consistent with an area of bilateral projection of up to $1^{\circ}$ either side of fixation (although in their study, this was observed after exposure durations of $2 \mathrm{sec}$; see Jordan \& Paterson, in press). Moreover, performance in that study was most accurate for spatial frequencies of 2 and 4 cycles/deg and least accurate for 1 and 8 cycles/deg, which resembles normal spatial frequency sensitivity (for further discussion, see Jordan \& Paterson, in press). As Fendrich et al. concluded, the precise nature and functioning of the hemispheric overlap remains to be determined but their findings indicate a substantial region of bilateral projection around the point of fixation (of about $2^{\circ}$ wide; a similar conclusion was drawn by Gazzaniga, 2000). This conclusion is inconsistent with the claims of SFT but is consistent with the findings of the present study, which implicate a region of bilateral projection that extends at least $0.80^{\circ}$ either side of fixation and supports accurate word recognition.

In sum, the findings reported in this article indicate that functional unilateral projections to different, contralateral hemispheres exist for extrafoveal presentations but provide no evidence of a division in hemispheric processing for foveal presentations. Indeed, from the pattern of wordnonword performance obtained, direct activation of LH processes of word recognition occurred with all displays except for extrafoveal displays projected to the $\mathrm{RH}$, indicating that only these displays provided no direct access to LH processes. These findings are highly problematic for SFT, which proposes a split in each fovea with the result that words in all locations up to the point of fixation project unilaterally to different hemispheres, and that this division in processing has substantive effects on word recognition. In contrast, our results provide no support for a functional split in foveal processing but are consistent with a substantial area of functional bilateral projection around the point of fixation, within which words activate processes specialized for word recognition equally well on each side of fixation and which supports the accurate recognition of even physically small, briefly presented stimuli.

\section{AUTHOR NOTE}

This research was supported by the Ulverscroft Foundation. Correspondence should be addressed to T. R. Jordan, School of Psychology, Faculty of Medicine and Biological Sciences, University of Leicester, Henry Wellcome Building, Leicester LE1 9HN, England (e-mail: prof .timjordan@leicester.ac.uk).

\section{REFERENCES}

AnLiKer, J. (1977). Eye movements on-line measurement, analysis, and control. In R. A. Monty \& J. W. Senders (Eds.), Eye movements and psychological processes (pp. 185-202). Hillsdale, NJ: Erlbaum.
Annett, M. (1970). A classification of hand preference by association analysis. British Journal of Psychology, 61, 303-321.

Ans, B., Carbonnel, S., \& Valdois, S. (1998). A connectionist multipletrace memory model for polysyllabic word reading. Psychological Review, 105, 678-723.

BaAyen, R. H., Piepenbrock, R., \& Gulikers, L. (1995). The CELEX Lexical Database (Release 2) [CD-ROM]. Philadelphia: University of Pennsylvania, Linguistic Data Consortium.

BARON, J., \& ThURSTON, I. (1973). An analysis of the word superiority effect. Cognitive Psychology, 4, 207-228.

Batt, V., Underwood, G., \& BRyden, M. P. (1995). Inspecting asymmetric presentations of words differing in informational and morphemic structure. Brain \& Language, 49, 202-223.

Bouma, H. (1973). Visual interference in the parafoveal recognition of the initial and final letters of words. Vision Research, 13, 767-782.

Bradshaw, J. L., \& Nettleton, N. C. (1983). Human cerebral asymmetry. Englewood Cliffs, NJ: Prentice Hall.

Brandt, T., Stephan, T., Bense, S., Yousry, T. A., \& Dieterich, M. (2000). Hemifield visual motion stimulation: An example of interhemispheric crosstalk. NeuroReport, 11, 2803-2809.

BRYSBAERT, M. (1994). Interhemispheric transfer and the processing of foveally presented stimuli. Behavioural Brain Research, 64, 151-161.

BRYSBAERT, M. (2004). The importance of interhemispheric transfer for foveal vision: A factor that has been overlooked in theories of visual word recognition and object perception. Brain \& Language, $\mathbf{8 8}$, 259-267.

Brysbaert, M., Vitu, F., \& Schroyens, W. (1996). The right visual field advantage and the optimal viewing position effect: On the relation between foveal and parafoveal word recognition. Neuropsychology, 10, 385-395.

Bub, D. N., \& Lewine, J. (1988). Different modes of word recognition in the left and right visual fields. Brain \& Language, 33, 161-188.

Bunt, A. H., \& MincKLER, D. S. (1977). Foveal sparing: New anatomical evidence for bilateral representation of the central retina. Archives of Ophthalmology, 95, 1445-1447.

Burgund, E. D., \& MarsoleK, C. J. (1997). Letter-case-specific priming in the right cerebral hemisphere with a form-specific perceptual identification task. Brain \& Cognition, 35, 239-258.

Carr, T. H., Davidson, B. J., \& Hawkins, H. L. (1978). Perceptual flexibility in word recognition: Strategies affect orthographic computation but not lexical access. Journal of Experimental Psychology: Human Perception \& Performance, 4, 674-690.

Carr, T. H., \& Pollatsek, A. (1985). Recognizing printed words: A look at current models. In D. Besner, T. G. Waller, \& G. E. MacKinnon (Eds.), Reading research: Advances in theory and practice (Vol. 5, pp. 1-82). San Diego: Academic Press.

Chiarello, C. (1988). Lateralization of lexical processes in the normal human brain: A review of visual half-field research. In H. A. Whitaker (Ed.), Contemporary reviews in neuropsychology (pp. 36-76). New York: Springer.

Dehaene, S., Cohen, L., Sigman, M., \& Vinckier, F. (2005). The neural code for written words: A proposal. Trends in Cognitive Neurosciences, 9, 335-341.

DrasDo, N. (1977). The neural representation of visual space. Nature, 266, 554-556.

ELLIS, A. W. (2004). Length, formats, neighbours, hemispheres, and the processing of words presented laterally or at fixation. Brain \& Language, 88, 355-366.

Ellis, A. W., Young, A., \& Anderson, C. (1988). Modes of word recognition in the left and right cerebral hemispheres. Brain \& Language, 35, 254-273.

Fendrich, R., Wessinger, C. M., \& Gazzaniga, M. S. (1996). Nasotemporal overlap at the retinal veridical meridian: Investigations with a callosotomy patient. Neuropsychologia, 34, 637-646.

Findlay, J. M., \& KaPOUla, Z. (1992). Scrutinization, spatial attention, and the spatial programming of saccadic eye movements. Quarterly Journal of Experimental Psychology, 45A, 633-647.

GaZZANiga, M. S. (2000). Cerebral specialization and interhemispheric communication: Does the corpus callosum enable the human condition? Brain, 123, 1293-1326.

Grainger, J., \& JACOBS, A. M. (1994). A dual read-out model of word context effects in letter perception: Further investigations of the word 
superiority effect. Journal of Experimental Psychology: Human Perception \& Performance, 20, 1158-1176.

Grainger, J., \& Jacobs, A. M. (1996). Orthographic processing in visual word recognition: A multiple read-out model. Psychological Review, 103, 518-565.

Hellige, J. B. (1993). Hemispheric asymmetry: What's right and what's left? Cambridge, MA: Harvard University Press.

Hunter, Z., Brysbaert, M., \& Knecht, S. (2007). Foveal word reading requires interhemispheric communication. Journal of Cognitive Neuroscience, 19, 1373-1387.

Jacobs, A. M., \& Grainger, J. (1994). Models of visual word recognition-Sampling the state of the art. Journal of Experimental Psychology: Human Perception \& Performance, 20, 1311-1334.

Johnston, J. C., \& McClelland, J. L. (1980). Experimental tests of a hierarchical model of word recognition. Journal of Verbal Learning \& Verbal Behavior, 19, 503-524.

Jones, B., \& SANTI, A. (1978). Lateral asymmetries in visual perception with and without eye movements. Cortex, 14, 164-168.

Jordan, T. R., \& Monteiro, A. (2003). Generating anagrams from multiple core strings employing user-defined vocabularies and orthographic parameters. Behavior Research Methods, Instruments, \& Computers, 35, 129-135.

JoRdAn, T. R., \& PATching, G. R. (2003a). Assessing effects of stimulus orientation on perception of lateralized words and nonwords. Neuropsychologia, 41, 1693-1702.

Jordan, T. R., \& Patching, G. R. (2003b). Perceptual interactions between bilaterally presented words: What you get is often not what you see. Neuropsychology, 17, 566-577.

Jordan, T. R., \& Patching, G. R. (2006). Assessing effects of fixation demands on perception of lateralized words: A visual window technique for studying hemispheric asymmetry. Neuropsychologia, 44, 686-692.

Jordan, T. R., Patching, G. R., \& Milner, A. D. (1998). Central fixations are inadequately controlled by instructions alone: Implications for studying cerebral asymmetry. Quarterly Journal of Experimental Psychology, 51A, 371-391.

Jordan, T. R., PATChing, G. R., \& MiLnER, A. D. (2000). Lateralized word recognition: Assessing the role of hemispheric specialization, modes of lexical access and perceptual asymmetry. Journal of Experimental Psychology: Human Perception \& Performance, 26, 1192-1208.

Jordan, T. R., Patching, G. R., \& Thomas, S. M. (2003a). Assessing the role of hemispheric specialization, serial-position processing and retinal eccentricity in lateralized word perception. Cognitive Neuropsychology, 20, 49-71.

Jordan, T. R., Patching, G. R., \& Thomas, S. M. (2003b). Asymmetries and eccentricities in studies of lateralized word recognition: A response to Nazir. Cognitive Neuropsychology, 20, 81-89.

JoRdAn, T. R., \& PATERSON, K. B. (in press). Re-evaluating split-fovea processing in word recognition: A critical assessment of recent research. Neuropsychologia.

Jordan, T. R., Paterson, K. B., Kurtev, S., \& Xu, M. (in press-a). Do fixation cues ensure fixation accuracy in split-fovea studies of word recognition? Neuropsychologia.

Jordan, T. R., Paterson, K. B., Kurtev, S., \& Xu, M. (in press-b). Re-evaluating split-fovea processing in word recognition: Effects of word length during monocular viewing. Cortex.

Jordan, T. R., Paterson, K. B., \& Stachurski, M. (2008). Reevaluating split-fovea processing in word recognition: Effects of retinal eccentricity on hemispheric dominance. Neuropsychology, 22, 738-745.

Jordan, T. R., Paterson, K. B., \& Stachurski, M. (in press). Reevaluating split-fovea processing in word recognition: Effects of word length. Cortex.

Jordan, T. R., Redwood, M., \& Patching, G. R. (2003). Effects of form familiarity on perception of words, pseudowords, and nonwords in the two cerebral hemispheres. Journal of Cognitive Neuroscience, 15, 537-548.

Knecht, S., Deppe, M., Dräger, B., Bobe, L., Lohmann, H., RingleStein, E. B., \& Henningsen, H. (2000). Language lateralisation in healthy right-handers. Brain, 123, 74-81.

LaVIDOR, M., \& BaIley, P. J. (2005). Dissociations between serial posi- tion and number of letters effects in lateralized visual word recognition. Journal of Research in Reading, 28, 258-273.

Lavidor, M., Ellis, A. W., Shillcock, R., \& Bland, T. (2001). Evaluating a split processing model of visual word recognition: Effects of word length. Cognitive Brain Research, 12, 265-272.

LAVIDOR, M., ElLISON, A., \& WALSH, V. (2003). The cortical representation of centrally presented words: A magnetic stimulation study. Visual Cognition, 10, 341-362.

LAVIDOR, M., \& WALSH, V. (2004). The nature of foveal representation. Nature Reviews Neuroscience, 5, 729-735.

LEFF, A. P. (2004). A historical review of the representation of the visual field in primary visual cortex with special reference to the neural mechanisms underlying macular sparing. Brain \& Language, 88, 268-278.

Leventhal, A. G., Ault, S. J., \& Vitek, D. J. (1988). The nasotemporal division in primate retina: The neural bases of macular sparing and splitting. Science, 240, 66-67.

Lindell, A. K., \& Nicholls, M. E. R. (2003). Cortical representation of the fovea: Implications for visual half-field research. Cortex, 39, 111-117.

LofTus, G. R., \& MAsson, M. E. J. (1994). Using confidence intervals in within-subject designs. Psychonomic Bulletin \& Review, 1, 476-490.

Loomis, J. M. (1978). Lateral masking in foveal and eccentric vision. Vision Research, 18, 335-338.

Manelis, L. (1974). The effect of meaningfulness in tachistoscopic word perception. Perception \& Psychophysics, 16, 182-192.

Martin, C. D., Thierry, G., Démonet, J. F., Roberts, M., \& Nazir, T. (2007). ERP evidence for the split fovea theory. Brain Research, 1185, 212-220.

McClelland, J. L., \& Johnston, J. C. (1977). The role of familiar units in perception of words and nonwords. Perception \& Psychophysics, 22, 249-261.

McClelland, J. L., \& Rumelhart, D. E. (1981). An interactive activation model of context effects in letter perception: Part 1. An account of basic findings. Psychological Review, 88, 375-407.

McClelland, J. L., \& Rumelhart, D. E. (1988). Explorations in parallel distributed processing. Cambridge, MA: MIT Press.

O'REgAN, J. K. (1981). The convenient viewing position hypothesis. In D. F. Fisher, R. A. Monty, \& J. W. Senders (Eds.), Eye movements, cognition, and visual perception (pp. 289-298). Hillsdale, NJ: Erlbaum.

O'Regan, J. K., Lévy-Schoen, A., Pynte, J., \& Brugaillère, B. (1984). Convenient fixation location within isolated words of different length and structure. Journal of Experimental Psychology: Human Perception \& Performance, 10, 250-257.

Paap, K. R., Newsome, S. L., McDonald, J. E., \& Schvaneveldt, R. W. (1982). An activation-verification model for letter and word recognition: The word-superiority effect. Psychological Review, 89, 573-594.

Patching, G. R., \& JoRdan, T. R. (1998). Increasing the benefits of eye-tracking devices in divided visual field studies of cerebral asymmetry. Behavior Research Methods, Instruments, \& Computers, 30, 643-650.

Plaut, D. C., McClelland, J. L., Seidenberg, M. S., \& Patterson, K. (1996). Understanding normal and impaired word reading: Computational principles in quasi-regular domains. Psychological Review, 103, 56-115.

Querné, L., Eustache, F., \& Faure, S. (2000). Interhemispheric inhibition, intrahemispheric activation, and lexical capacities of the right hemisphere: A tachistoscopic, divided visual-field study in normal subjects. Brain \& Language, 74, 171-190.

Rayner, K., \& Pollatsek, A. (1989). The psychology of reading. Englewood Cliffs, NJ: Prentice Hall.

ReICHER, G. M. (1969). Perceptual recognition as a function of meaningfulness of stimulus material. Journal of Experimental Psychology, 81, 275-280.

Reinhard, J., \& TrauzetTel-Klosinski, S. (2003). Nasotemporal overlap of retinal ganglion cells in humans: A functional study. Investigative Ophthalmology \& Visual Science, 4, 1568-1572.

Reuter-Lorenz, P. A., \& BAynes, K. (1992). Modes of lexical access in the callosotomized brain. Journal of Cognitive Neuroscience, $\mathbf{4}$, 155-164. 
Rumelhart, D. E., \& McClelland, J. L. (1982). An interactive activation model of context effects in letter perception: Part 2. The contextual enhancement effect and some tests and extensions of the model. Psychological Review, 89, 60-94.

Seidenberg, M. S., \& McClelland, J. L. (1989). A distributed, developmental model of word recognition and naming. Psychological Review, 96, 523-568.

Shillcock, R. [C.], Ellison, T. M., \& Monaghan, P. (2000). Eyefixation behavior, lexical storage, and visual word recognition in a split processing model. Psychological Review, 107, 824-851.

ShILlCock, R. C., \& McDonald, S. A. (2005). Hemispheric division of labour in reading. Journal of Research in Reading, 28, 244-257.

Spoenr, K. T., \& Smith, E. E. (1975). The role of orthographic and phonotactic rules in perceiving letter patterns. Journal of Experimental Psychology: Human Perception \& Performance, 1, 21-34.

Stevens, M., \& Grainger, J. (2003). Letter visibility and the viewing position effect in visual word recognition. Perception \& Psychophysics, 65, 133-151.

STONE, J. (1966). The naso-temporal division of the cat's retina. Journal of Comparative Neurology, 126, 585-600.

Stone, J., Leicester, J., \& Sherman, S. M. (1973). The naso-temporal division of the monkey's retina. Journal of Comparative Neurology, 150, 333-348.

Sugishita, M., Hamilton, C. R., Sakuma, I., \& Hemmi, I. (1994). Hemispheric representations of the central retina of commissurotomized subjects. Neuropsychologia, 32, 399-415.

TERrace, H. S. (1959). The effects of retinal locus and attention on the perception of words. Journal of Experimental Psychology, 58, 382-385.

Trauzettel-Klosinski, S., \& Reinhard, J. (1998). The vertical field border in hemianopia and its significance for fixation and reading. Investigative Ophthalmology \& Visual Science, 39, 2177-2186.

Wheeler, D. D. (1970). Processes in word recognition. Cognitive Psychology, 1, 59-85.

\section{NOTES}

1. Recent evidence has revealed that instructions to fixate a designated point do not ensure fixation accuracy even when combined with a secondary task (e.g., identifying a digit presented at the required fixation location). In fact, when participants were instructed to fixate a fixation point, accurate fixation occurred on only $25 \%$ of the trials, and a secondary fixation task produced no significant improvement in this level of accuracy (Jordan, Paterson, Kurtev, \& Xu, in press-a).

2. The primary benefit of the Reicher-Wheeler task for studies of hemispheric asymmetry is that it provides evidence of LH dominance for word recognition that is not contaminated by perceptual bias or guesswork and yet has repeatedly shown (since its inception by Reicher, 1969) sensitivity to processes of word perception. In particular, one problem often ignored in laterality research is that participants may be more able to guess words' identity when they are presented to the right of fixation simply because the highly informative beginnings of words can be seen more easily than when the same words are presented to the left of fixation, and this can produce spurious indications of an LH advantage. The Reicher-Wheeler task overcomes this problem by using a forced choice between two alternatives that differ in ways that cannot be identified from any other part of the stimulus. This also makes the task ideally suited for comparing performance between words and nonwords that may otherwise be distorted by the redundancy inherent in word stimuli. Thus, although these crucial aspects of the Reicher-Wheeler task have not always been fully understood (see, e.g., Lavidor \& Bailey, 2005), the task is ideal for measuring word and nonword performance at different retinal eccentricities without contamination from asymmetries in the visibility of partial information.

(Manuscript received August 13, 2008; revision accepted for publication October 20, 2008.) 